\title{
Glioblastoma multiforme
}

\section{Reporte de un caso}

\author{
Rocha Parra Miguel Angel*
}

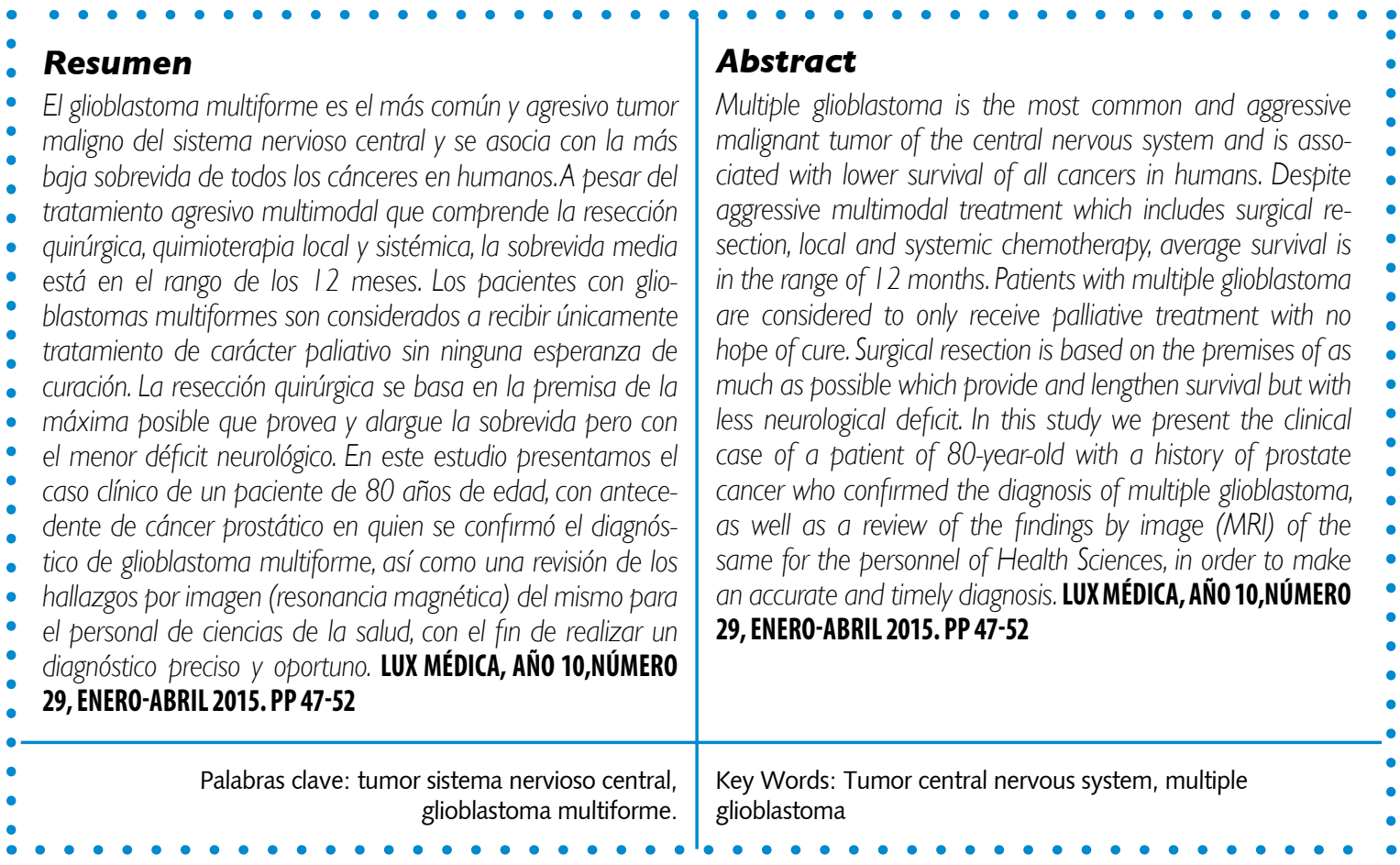

\section{Introducción}

EL glioblastoma es el tumor mas común y maligno entre las neoplasias de la glía. Los tumores astrocíticos se dividen en dos categorías básicas: circunscritos (grado I) o difusos (grados II-IV). Todos los astrocitomas difusos tienden a progresar al grado IV, el cual es sinónimo de glioblastoma multiforme (GBM). El GBM se caracteriza por ser un tumor con una marcada neovascularidad, incremento

\footnotetext{
* Médico residente de 3er año de la especialidad de Radiología e Imagenología Diagnóstica y Terapéutica del Centenario Hospital Miguel Hidalgo, Aguascalientes, Ags.

Fecha de recibido: 21 de enero 2015

Fecha de aceptación: 28 de febrero 2015

Correspondencia: Dr Miguel Ángel Rocha Parra, médico residente del tercer año de la especialidad de Radiología e Imagenología Diagnóstica y Terapéutica del Centenario Hospital Miguel Hidalgo. Calle Galeana Sur 465, Colonia Obraje. Código Postal 20230. Aguascalientes, Ags., México. Teléfono 01(449)9946720. Correo electrónico doc.rocha@hotmail.com
} 
en la mitosis, mayor grado de celularidad, pleomorfismo nuclear y evidencia microscópica de necrosis. ${ }^{1}$

Puede manifestarse a cualquier edad, pero afecta principalmente a adultos, con un pico de incidencia entre los 45 y los 70 años. Se presenta habitualmente en los hemisferios cerebrales, siendo menos frecuente su localización en el tronco del encéfalo o la médula espinal. ${ }^{2}$

El glioblastoma puede desarrollarse a partir de un astrocitoma difuso (grado II), o de un astrocitoma anaplásico (grado III), que en estos casos se denominan secundarios, pero con mayor frecuencia ocurre de novo, sin ninguna evidencia de neoplasia previa, denominándose en este caso primario. Es el tumor cerebral primario mas frecuente, su incidencia es de solo 2-3 casos por cada 100,000 habitantes en Europa y Norteamérica.

Múltiples anormalidades genéticas se han asociado con el desarrollo de GBM: en algunos casos es heredada (ej. Síndrome de Li-Fraumeni); en otros casos, la alteración genética aparece como resultado de una mutación en un oncogen o deterioro del gen supresor tumoral p53.

El hallazgo imagenológico mas común del $G M B$ es una masa grande y heterogénea en la sustancia blanca supratentorial que ejerce un efecto de masa considerable, con captación de contraste en forma anular y con un área central necrótica. Con menor frecuencia, el GBM puede ocurrir cerca de la duramadre, o en el cuerpo calloso, fosa posterior y médula espinal. El GBM típicamente contiene áreas centrales de necrosis, paredes irregulares engrosadas, y está rodeado por edema vasogénico extenso, aunque el tumor también puede presentar paredes redondeadas y delgadas, edema escaso, o una apariencia quística con nódulo mural. Comúnmente metastatizan desde su localización original por extensión directa a través de los tractos de la sustancia blanca; sin embargo puede ocurrir diseminación a través del liquido cefalorraquídeo, subependimario y hematógeno. ${ }^{1-5}$

Debido al rápido crecimiento y al mal pronóstico de este tumor, el rol de los radiólogos es mas importante que nunca en el diagnóstico preciso y oportuno.

\section{Presentación del caso clínico}

Hombre de 80 años de edad, con antecedente familiar de cáncer de próstata, quien sufrió caída desde su propia altura y se golpeó el lado izquierdo de la cabeza. Refiere no recordar detalles de la caída y tuvo que ser despertado por familiares. El paciente presentó dificultad persistente con el equilibrio y la memoria, motivo por el cual llega a sala de urgencias donde se le realizó una tomografía computada (TC) del cráneo 
simple, que mostró resultados anormales. Los resultados de la resonancia magnética (RM) de encéfalo confirmaron la presencia de una lesión heterogénea que realza tras la aplicación del medio de contraste localizada en los lóbulos temporal y parietal derechos. La TC de tórax, abdomen y pelvis fue negativa para la enfermedad metastásica. Al ser interrogado, el paciente refirió dolores de cabeza temporales bilaterales ocasionales; del lado izquierdo del cuerpo con debilidad y creciente deterioro de la audición, el habla, la concentración y la memoria.

Al ingreso, el paciente comenzó con mejoría significativa en la discapacidad de la habla y debilidad. En el quinto día después de la admisión, se sometió a un solo tratamiento con radiación. En la madrugada del día 11 después de la admisión, se le encontró muerto. Se le realizó autopsia, sin encontrar hallazgos asociados.

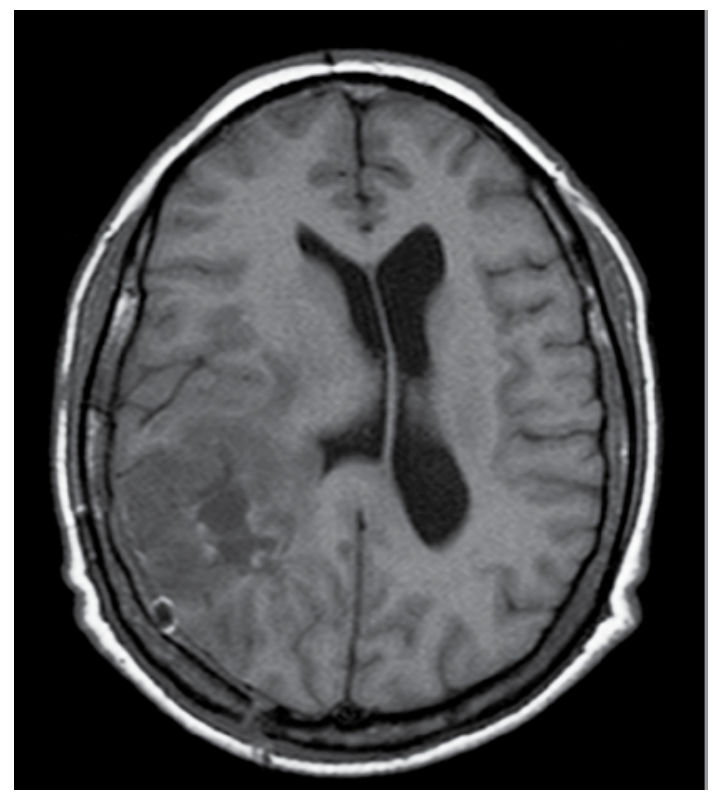

Figura 1. Imagen axial de RM de encéfalo en secuencia Tl que muestra una masa de localización temporo-parietal derecha, heterogénea, con limites poco definidos, áreas centrales de necrosis, disminución en la amplitud de los surcos e importante efecto de masa, condicionando desplazamiento de la línea media.

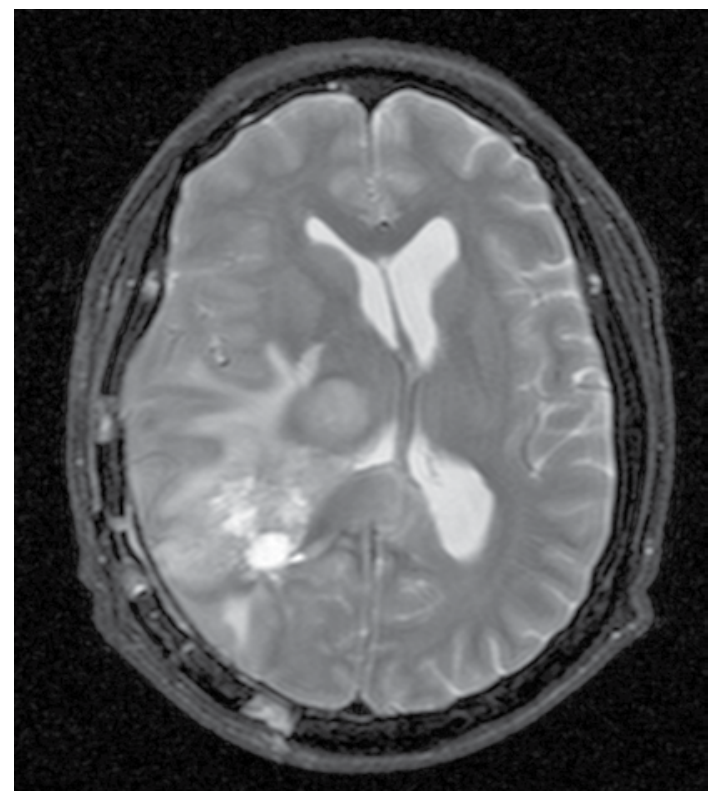

Figura 2. Corte axial de RM de encéfalo en secuencia potenciada T2, que permite observar las áreas centrales de necrosis y los hallazgos ya descritos. 


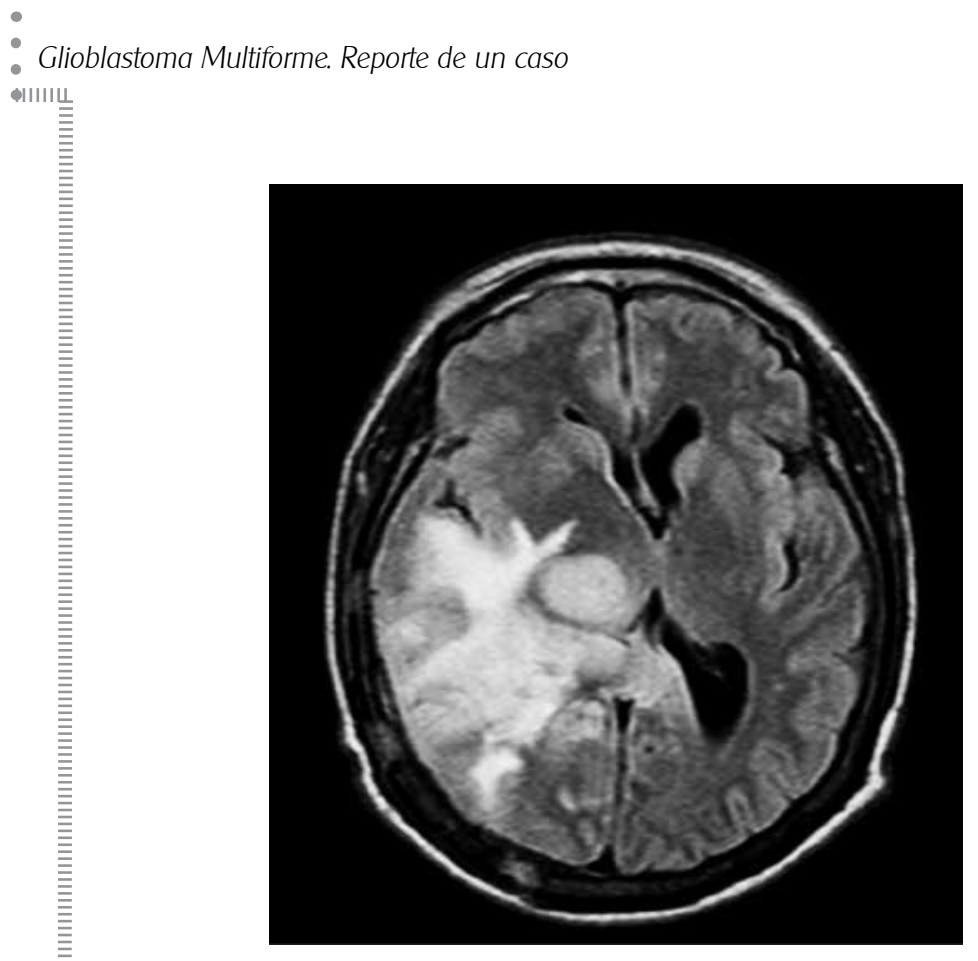

Figura 3. Corte axial de RM de encéfalo en secuencia potencia FLAIR, donde es mas evidente el extenso edema en la sustancia blanca, que produce la tumoración.

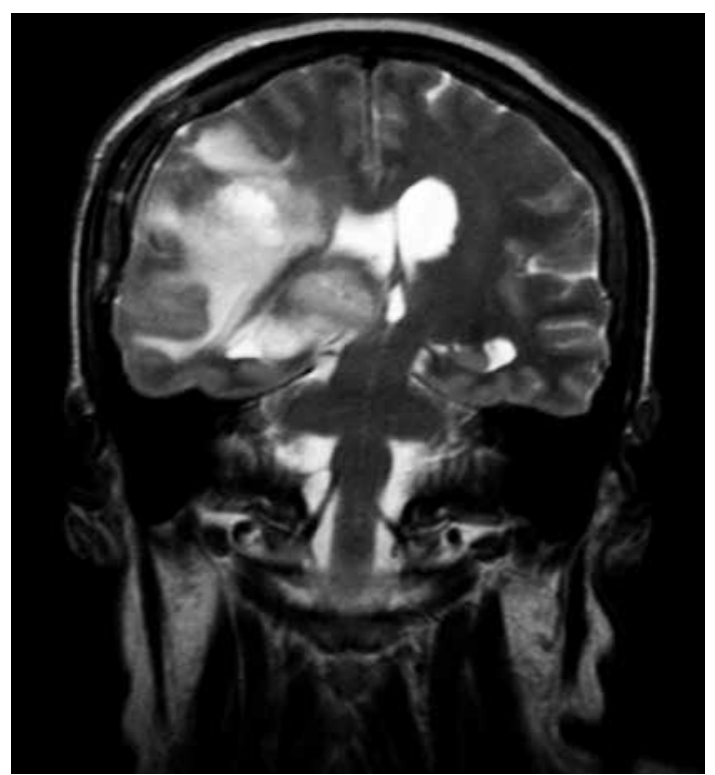

Figura 4. Corte coronal de RM de encéfalo en secuencia potenciada T2 que nos muestra la importante desviación de la línea media así como del tronco encefálico hacia la izquierda condicionada por la tumoración.

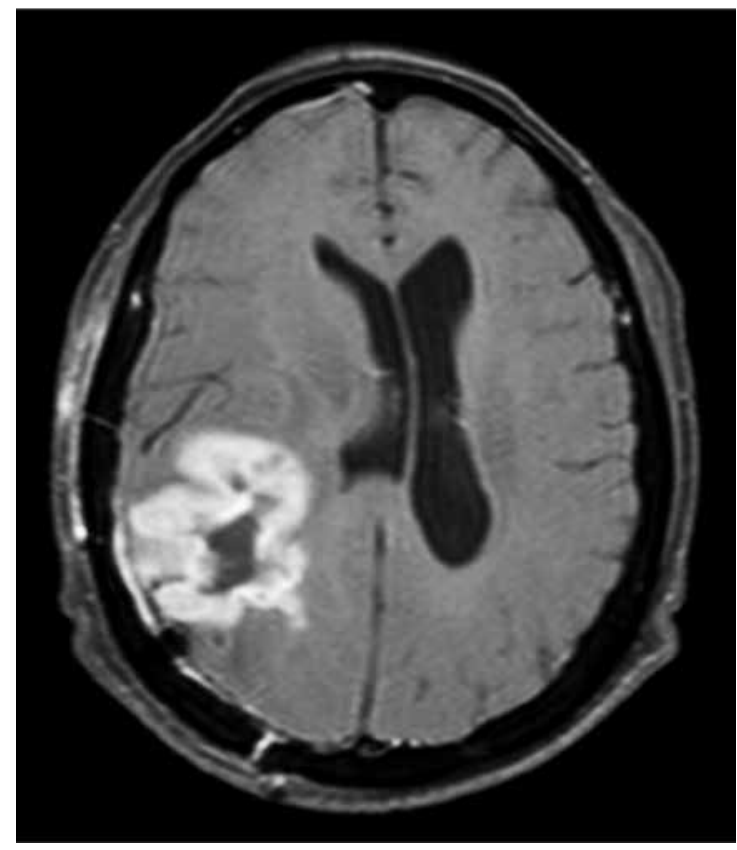




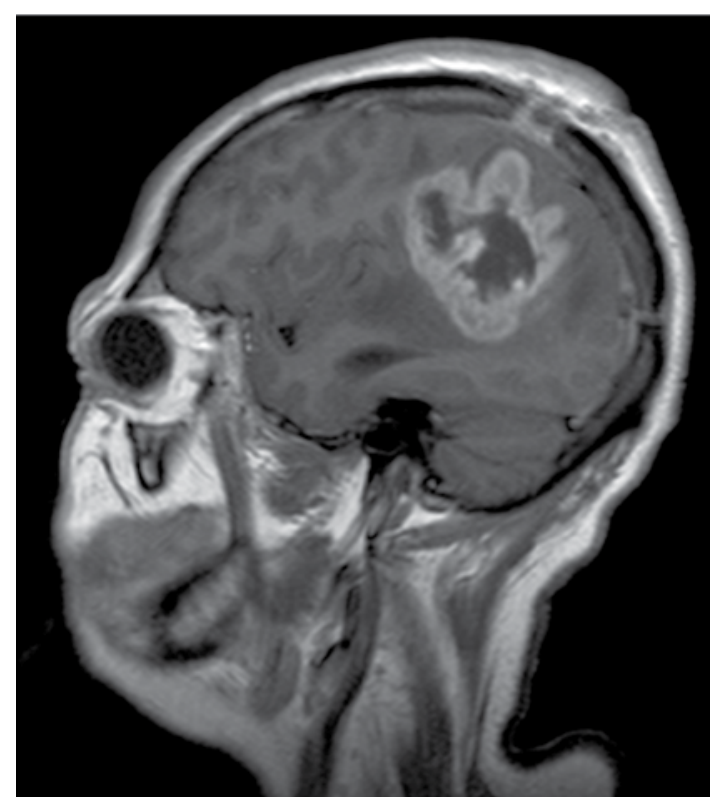

$5 B$

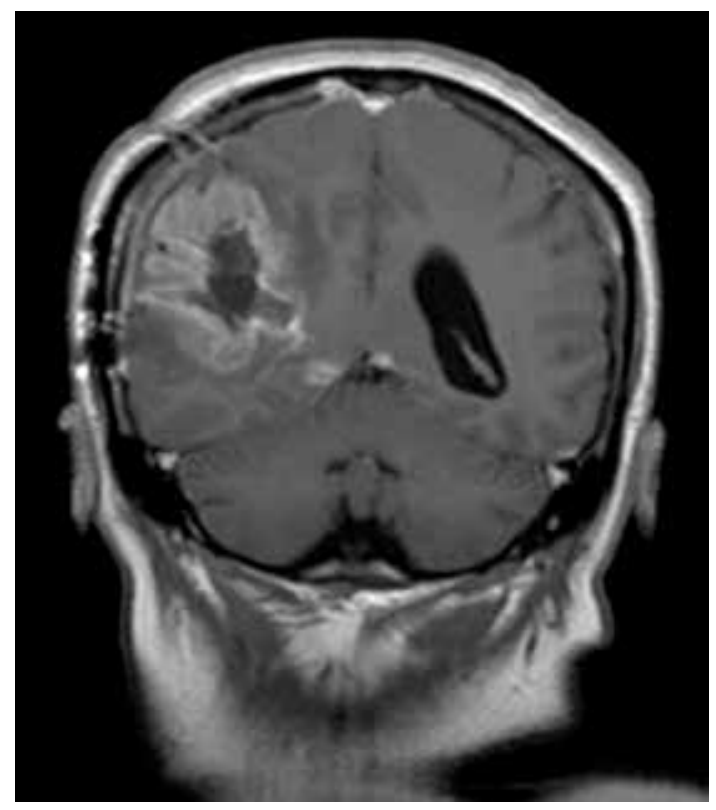

$5 C$

Figura 5. Cortes axial (A), coronal (B) y sagital (C) de RM de encéfalo en secuencia T1 con contraste, donde se hace evidente el importante realce de la periferia tumoral, mostrando paredes engrosadas e irregulares; nótese la ausencia de realce en el centro de la lesión, dato que confirma el centro necrótico.

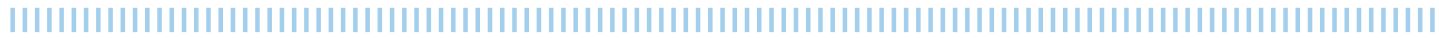

\section{Discusión}

En el caso presentado, se observa que los síntomas y hallazgos por imagen no muestran variación en comparación con otros casos de glioblastoma multiforme confirmados, sin embargo, el antecedente de cáncer prostático en este caso, podría hacernos sospechar en enfermedad metastásica antes que un tumor primario. Es por eso que la evaluación completa de las características por imagen siempre se deberá integrar con la clínica y los antecedentes del paciente para llegar al diagnóstico preciso. El glioblastoma multiforme es el tumor cerebral primario maligno más común, con una prevalencia del $12-15 \%$ de todas las neoplasias intracraneales. El pronóstico es sombrío. A pesar de los tratamientos estándar, los cuales incluyen resección quirúrgica, terapia de radiación postoperatoria, y múltiples protocolos de quimioterapia, más del $75 \%$ de los pacientes mueren dentro de los 18 meses siguientes. El pronóstico no ha cambiado significativamente desde 1970. 3,4,6,7

El glioblastoma ocurre con mayor frecuencia en los hemisferios cerebrales de adultos entre 45 y 70 años de edad. Es raro en el cerebelo y médula espinal, y menos del $10 \%$ de los casos se encuentran en niños, en quienes el tronco cerebral se afecta con mayor frecuencia. La mayoría de los glioblastomas crecen sin presentar evidencia de una lesión precursora de bajo grado, después de un curso clínico corto de aproximadamente 3 meses. La edad media de los pacientes que presentan un glioblastoma primario es de 55 años. Los glioblastomas secundarios están caracterizados por un curso clínico más prolongado y se encuentran en una población de pacientes mas jóvenes (edad promedio 40 años).

La RM con gadolinio convencional es la técnica estándar para la evaluación del glioblastoma y típicamente muestra una gran 
masa heterogénea en el hemisferio cerebral con necrosis, hemorragia y realce. En los adultos, el diagnóstico diferencial de una masa intraaxial solitaria, heterogénea con áreas de necrosis y que muestra realce tras la aplicación del medio de contraste, también incluye la presencia de metástasis o un absceso. Aunque la enfermedad metastásica exhibe una amplia variedad de apariencias, el gran tamaño de la lesión y la falta de multiplicidad como en este caso sugerían más un tumor primario que una metástasis. Un absceso cerebral también puede presentar hallazgos radiológicos distintivos, por ejemplo, un absceso no elevaría la relación creatina-colina, en la espectroscopía por RM. Múltiples técnicas de resonancia magnética avanzada han demostrado mejorar tanto la detección de tumores y la evaluación prospectiva del grado del tumor.

En la espectroscopía, la elevación de la colina y la depresión de NAA (N-Acetil-aspartato) sugieren tumor; las distin- tas proporciones de los metabolitos (colina-creatina, colina-NAA, creatina-NAA, mioinositol-creatina), exhiben relaciones del grado tumoral. En las imágenes de RM de perfusión, el volumen sanguíneo cerebral relativo se incrementa en los astrocitomas de grado más alto. La RM también es ampliamente utilizada en la evaluación después del tratamiento del tumor. ${ }^{8}$

Se están haciendo progresos en el diagnóstico y tratamiento del glioblastoma, y gran parte del trabajo implica una comprensión de las mutaciones y la expresión diferencial de los genes que se han asociado con los glioblastomas primarios y secundarios. Los glioblastomas primarios están asociados con la amplificación y la sobreexpresión del receptor de superficie celular EGFR, mutaciones en PTEN, y anormalidades en el cromosoma 10, entre otros factores. Los glioblastomas secundarios a menudo presentan mutaciones en TP53, así como anormalidades en los cromosomas $19 q$ y $10 q .{ }^{7}$

\section{Conclusión}

El tratamiento del GBM ha evolucionado en los últimos años. Sabiendo que la cirugía sola no es curativa, se ha intentado mediante la integración de otras modalidades, como radioterapia y quimioterapia, prolongar el tiempo de sobrevida. El principal objetivo de la exéresis, lo más completa posible, es la confirmación diagnóstica y la reducción de la masa tumoral, la cual es técnicamente difícil por la naturaleza infiltrante y el rápido crecimiento que caracteriza a esta tumoración maligna.

\section{Bibliografía}

1. Osborn Anne, Salzman Karen L., Barkovich A. James, et al. Diagnostico por imagen Cerebro. Segunda edición. Madrid, España. Marban. 2011.

2. Grossman, Yuzmen. Neurorradiologia. Segunda edición.

3. Chang $\mathrm{KH}$, Song IC, Kim SH, et al. In vivo single- voxel proton MR spectroscopy in intracranial cystic masses. AJNR Am J Neuroradiol 1998;19(3):401- 405.

4. Kleihues P, Burger PC, Collins VP, Newcomb EW, Ohgaki $\mathrm{H}$, Cavenee WK. Glioblastoma. In: Kleihues P, Cavenee WK, eds. Pathology and genetics of tumors of the nervous system. Lyon, France: IARC, $2000 ; 29-39$.
5. Stark AM, Nabavi A, Mehdorn HM, Blo ?mer U. Glioblastoma multiforme: report of 267 cases treated at a single institution. Surg Neurol 2005; 63:162-169.

6. Kleihues $\mathrm{P}$, Louis DN, Scheithauer BW, et al. The WHO classification of tumors of the nervous system. J Neuropathol Exp Neurol 2002;61(3):215- 225.

7. Goebell E, Paustenbach S, Vaeterlein O, et al. Lowgrade and anaplastic gliomas: differences in architecture evaluated with diffusion-tensor MR imaging. Radiology 2006;239(1):217-222.

8. Law $M$, Yang $S$, Wang $H$, et al. Glioma grading: sensitivity, specificity, and predictive values of perfusion MR imaging and proton MR spectroscopic imaging compared with conventional MR imaging. AJNR Am J Neuroradiol 2003;24:1989 1998. 